\title{
Sophie Gagnon-Roberge (2019). Despertar el placer por la lectura. Actividades y sugerencias para todos los gustos. Madrid: Narcea. 108 págs. ISBN: 978-84-277- 2626-0. ePdf: 978-84-277-2627-7. ePub: 978-84-277-2628-4
}

\author{
María Pilar Moragón Arias ${ }^{1}$ \\ ${ }^{1}$ Universidad de Vigo.mariapilarmoragon@uvigo.es
}

Recibido: $11 / 11 / 2020$

Aceptado: 20/3/2021

Copyright (C)

Facultad de CC. de la Educación y Deporte. Universidad de Vigo

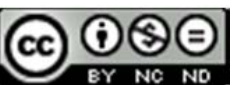

Dirección de contacto:

María Pilar Moragón Arias

Facultade de Ciencias da Educación e do

Deporte

Campus A Xunqueira, s/n

36005 Pontevedra
Traemos a colación un libro de hace casi dos años que, sin embargo, tiene muchas cosas que aportar porque su temática no pasa ni pasará de moda y ofrece una utilidad fuera de toda duda para ayudar a fortalecer una de las herramientas fundamentales del proceso educativo y formativo: la lectura. La autora, Sophie Gagnon-Roberge, profesora de enseñanza media canadiense-francófona así lo sostiene, con vehemencia, incidiendo en la necesidad de propiciar que la lectura-herramienta, se convierta en una actividad placentera y adictiva que se inserte de forma natural en el proceso de aprendizaje por parte de los alumnos y alumnas de todos los niveles educativos. Es decir, que la lectura vaya más allá de las implicaciones e imposiciones curriculares de determinados títulos y autores para que el lector o la lectora adolescentes se conviertan en "independientes", en amantes de la lectura per se, convirtiéndola en un ingrediente fundamental de sus vidas.

La constatación del período de "crisis de lectura" que supone la preadolescencia y la adolescencia, tal y como le demuestra su experiencia docente, la lleva a idear y poner en práctica estrategias, trucos y actividades para conseguir abrir la "puerta mágica" que lleva a la lectura. A través del desarrollo de estas propuestas, que va valorando según su éxito mayor o menor, la autora incide en lo que considera seis grandes ejes de la lectura que se corresponden con cada uno de los capítulos: la necesidad de que los alumnos tengan una proximidad y accesibilidad constante a los libros en el centro y en las aulas; transmitir como docentes la pasión por la lectura "predicando" con el ejemplo y ofreciendo modelos atractivos de lector, porque los jóvenes leen si sus padres leen y si su maestro lee en su presencia; insertar la lectura en el día a día del aula aprovechando cualquier momento y circunstancia para propiciar actividades lectoras; interesarse y acompañar constantemente a los lectores y lectoras con dificultades, buscando la adaptación de los títulos a las necesidades e intereses de los sujetos; ofrecer siempre una posibilidad amplia donde elegir las lecturas, sin dirigismo pero sí con orientación reflexiva y argumentada por parte del docente; y sobre todo, propiciar y desarrollar mediante diversas actividades y estrategias que los alumnos y las alumnas compartan y comenten lo que leen para crear una cadena de lectores que se retroalimenten en el proceso. Es cierto que, en tiempos de pandemia, algunas de estas estrategias se nos antojan poco recomendables por lo que tienen de posibilitar contactos estrechos no deseados, pero ello no las invalida para su desarrollo en tiempos "normales". 
Pero también es interesante constatar cómo la autora aboga por lograr una síntesis enriquecedora de la actividad lectora tradicional con las posibilidades abiertas por las nuevas tecnologías. Es cierto que los adolescentes se han curtido en la cultura del whatsap y de twitter, de la economía de las letras y de las palabras en las expresiones, en unos tiempos acelerados peleados con el reposo y la reflexión que precisa una buena lectura comprensiva. Sin embargo, esta competencia puede tornarse en alianza si se sabe dirigir hacia unos fines bien definidos, aprovechando esas herramientas tecnológicas con la creación de blogs, foros de discusión o todas las opciones de feedback que ofrecen las redes sociales entre autor-lector, lector-autor o lector-lector.

Hay que decir que la panoplia de propuestas y actividades es amplia y original, seguramente con muchas posibilidades de éxito en su inserción en el aula. Cada uno puede extraer, para su aula y para su nivel educativo, aquello que más se adapte a sus circunstancias, y por eso el valor del libro como guía es indudable. En esta línea va la sugerencia de lecturas en varias escalas de dificultad, que en esta edición se ha tenido el acierto de ceñir a las que aparecen publicadas en castellano, y articuladas según géneros literarios: aventuras, cómics -la autora es consciente de la importancia de este formato entre los adolescentes y aboga por potenciar sus virtudes como elemento de consolidación de los hábitos lectores-, distopías, historias fantásticas, histórico, realista, ciencia-ficción y suspense.

Si algún pero podemos ponerle a este excelente libro, es que no ponga en valor otro tipo de lecturas que consideramos necesarias en el mundo actual. No cabe duda que es importante despertar el placer por la lectura de literatura y obras de ficción que nos convierten en personas más plenas, sensibles y creativas, pero para conseguir esa creación de lectores independientes es imprescindible también, en nuestra opinión, que se amplíe al conocimiento y disfrute de otro tipo de libros: echamos de menos la referencia a la divulgación científica, a los relatos históricos no novelados, a la descripción geográfica de paisajes, a la introducción a conceptos y términos económicos imprescindibles en el día a día, a las biografías... Todos ellos constituyen igualmente ejercicios que abren la puerta a lectores independientes y que crean adición además de formar y crear ciudadanos y ciudadanas críticos, independientes y activos.

En estas mismas páginas se publicó hace unos años la reseña de un libro de José Manuel Marrasé, uno de cuyos capítulos trataba precisamente de la importancia de fomentar el placer por la lectura, y unos de sus párrafos nos impactó y nos parece oportuno reproducirlo aquí y ahora, porque está muy relacionado con el contenido y la filosofía de esta obra: "Leer es vivir, aprender y soñar. Todo nos es dado en un pequeño objeto; el universo entero, todas las sensaciones, están contenidos tras los códigos que interpretamos en una pantalla o en un trozo de papel, después de pulsar en el teclado táctil o después de acariciar las páginas con los dedos, en un gesto cómplice y solidario con el autor, con el resto de lectores y contigo mismo. Nuestros alumnos aprenden a aprender y a vivir mientras estimulan de forma dual la razón y la pasión, el conocimiento y las emociones. En esa estimulación los buenos libros aquellos que nos despiertan, que nos hacen comprender o soñar- juegan un papel fundamental (...) Nuestra facilidad para pensar de forma correcta, para articular un argumento lógico o para describir con detalle una situación, nuestra sensibilidad y creatividad se alimentan, sin que nos demos cuenta, de los libros. Tenemos que 
pensar en ello para percibirlo. Cuestiones como el respeto hacia los demás, la aportación personal a la sociedad, la predisposición a la colaboración y la cooperación, la comprensión de otras culturas y religiones, la visión abierta del mundo o la formación de un pensamiento libre y crítico son, hoy, objetivos prioritarios de una educación de calidad" (Marrasé, 2019). Poco más hay que añadir ante esta declaración de amor a la lectura.

$\mathrm{Y}$ el libro de Gagnon-Roberge es precisamente otra declaración de amor a la lectura que además nos guía por unas sendas difíciles, como son las que se transitan en el día a día en el aula, y por ello constituye, además de un placer lector en sí mismo, un valioso caudal de aprendizaje y de experiencias para ayudarnos a mejorar como docentes. Al fin y al cabo "si la escuela no pone en valor la lectura y los lectores ni enseña todo el potencial de goce que entrañan los libros, ¿quién lo hará?" (p. 41). 